who introduced group theory into physics (p.145): that had been done by Wigner in the late 1920 s. Group theory then became one of the customary tools of theoretical physicists. Gell-Mann applied it ingeniously and successfully to the problems of particle physics.

In two cases Snow's tendency to sum up people in a few sentences leads to injustice. On p.112 he states bluntly that "General Groves was a singularly bad choice for his job". I have no well-founded personal opinion, but I notice that A.H. Compton writes in his Atomic Quest - by a curious coincidence also on p.112 - "The nation was fortunate indeed in the selection of General Groves for this task". Also, it cannot be denied that Groves's short-term mission was efficiently accomplished. The second case is worse. On p.26 Snow writes

. . L Lenard who, incidentally, as an old man was one of the only two eminent German scientists who became active spokesmen for the Nazi faith. (The other was Werner Heisenberg, a great theoretician ....).

Such parenthetic calumny should not go uncorrected. Certainly, Heisenberg was a German patriot. He loved his country; the German language and German culture meant much to him (but in the early 1920s the Jugendbewegung to which he belonged was not a nationalistic group). We may regret that he let his love for his country prevail over his objections to the Nazis, we may wish that he had taken a firmer and more courageous stand against them. And I admit that on the one occasion I met him during the war he showed little

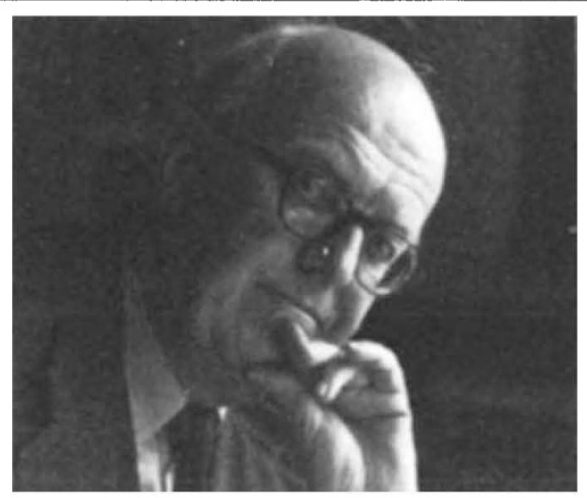

C.P. Snow 1905-1981

understanding for the feelings of people in an occupied country. But he always maintained his integrity as a physicist and at one time he was even under severe attack by members of the Lenard group, because he continued to express his belief in quantum theory and relativity. It is utterly wrong to mention him in one breath with Lenard.

Nevertheless, despite these detailed criticisms, I consider The Physicists a valuable book. Its theme is important, its basic structure sound and it contains many incisive remarks and interesting side-lights. I read it with pleasure and profit, and am convinced that many will do likewise.

H.B.G. Casimir studied theoretical physics at Leiden, Copenhagen and Zürich, worked in low temperature physics at Leiden and later joined the Philips Company at Eindhoven. He is a foreign member of the Royal Society and a former President of the European Physical Society.

\title{
Philosophy in an uncertain world
}

\section{John Polkinghorne}

Divine and Contingent Order. By Thomas F. Torrance. Pp.162. ISBN 0-19-826658-8. (Oxford University Press: 1981.) £9.50, $\$ 27.59$.

PROFESSOR Tom Torrance is a distinguished theologian, the chief apostle in this country of Karl Barth, whom many would regard as the most significant figure in twentieth-century theology. In addition, Torrance is one of the few British theologians to have taken a serious interest in what science has to say about the world. This reflects itself in Torrance's strongly objectivist approach to theology, and it is no accident that one of his best known books is called Theological Science.

His latest work is concerned with the assessment of the significance of the contingency that we find in nature. We can distinguish at least four senses in which such contingency is present: (i) The laws of nature are not necessary, in the sense that their form cannot be determined by pure thought alone but has to bc obtained from experimental observation. The recognition and exploitation of this is what gave modern science its superiority over that of the ancient world. (ii) The parameters appearing in those laws, such as the fine structure constant, take values which can only be determined empirically. Sir Arthur Eddington tried to deny this in Fundamental Theory and came to grief. However an interesting gloss on the values of these constants is provided by the anthropic principle which recognizes limitations to be satisfied in a universe in which we can emerge as observers. Torrance only mentions this in a footnote; it deserved greater consideration on his part. (iii) In the great diversity of things that happen there are unforeseeableconcatenations of circumstance. This is the "chance" that Monod saw operating in the emergence of life and which for him (but not for me) caused the fabric of significance to crumble. (iv) There is the radical unpredictability of quantum mechanical observation and (I would say) the action of the will, both topics which we do not understand very well.

It seems important to discriminate between these four aspects of contingence,
Bioscience Titles

\section{from}

\section{Pitman}

\section{NEW}

\section{Quantitative Ethology}

The State Space Approach

D McFarland and A Houston

The only systematic approach to the subject available, this is the first book to combine functional and mechanistic explanations of

behaviour at a quantitative level. It provides a theoretical framework for researchers to co-ordinate the numerous discoveries and examples that stem from the field of modern ecology.

ISBN 027308417 8/Cased/ $\$ 17.50$

Associated Animal Behaviour Title

The Social Biology of Ants K Dumpert

Provides a comprehensive review of the social and family life of ants in different and eco-ethological

conditions.

ISBN 027308479 8/£20

\section{NEW}

Pests, Pathogens and

Vegetation

The Role of Weeds and Wild Plants in the Ecology of Crop Pests and Diseases

Fdited by J M Thresh

A collection of forty pieces by different authors dealing with numerous aspects of the role of weeds and wild plants in the ecology of crop diseases. A strong underlying ecological theme gives continuity to this work, which should be of interest to a wide range of biologists.

ISBN 027308498 4/Cased/£30

Associated Applied Biology Title

\section{Opportunities for}

\section{Increasing Crop Yields}

Fdited by Hurd, Biscoe and Dennis An important book discussing the most promising ways of achieving the maxiumum potential from different crops.

ISBN $027308481 \mathrm{X} /$ Cased/£24

Order from your bookseller, or use this advertisement as an order form: send it with your cheque/postal order to

CASHPOST SERVICE, BOOK CENTRE, SOUTHPORT PR9 9YF. If stocks are available, we guarantec to despatch your order within 48 hours.

Postage and Packing FREE. NAl $\% 11 / 81$

Pitman Books Limited, 39 Parker Street, London WC2B 5PB 
but I did not feel that Torrance always adequately observed the distinction.

As a matter of historical fact the Christian doctrine of creation helped men to recognize (i) and (ii) and so made possible the scientific revolution. By a curious twist, the Newtonian mechanical world view then tended to abolish the recognition of (iii) and (iv).

The presence of contingence in the world is combined with a high degree of intelligibility which enables us to understand it. Torrance says "The intelligibility of the universe provides science with its confidence but the contingence of the universe provides science with its challenge"' (p.58). Such a view of the world is certainly consistent with the doctrine that it is the work of the sovereign will of the Creator and that its rationality is the reflection of his mind. Torrance seems to argue that only such a doctrine is possible but I cannot agree that there is that degree of intellectual compulsion. He sees creation as implying two complementary aspects. First, the world is wholly dependent on God since without his sustaining it would collapse back into nothingness. From this comes its contingent order. Second, the world is other than God (no pantheism!) so that he has made it to stand apart from him. The first aspect is the concern of theology; the second that of science whose method is to proceed etsideus non daretur, as if God did not exist. A true understanding requires a synthesis of these aspects.

A test of any world view is its understanding of evil. Torrance equates evil with disorder but nevertheless (rightly I believe) does not go along with Augustine and Aquinas in seeing it as just the absence of good. I thought his discussion needed a more thorough-going eschatological dimension. Also, I did not always recognize the world of science as Torrance described it. He attributes a release from the shackles of Newtonian necessity to the creation of the field concept and to the genius of Einstein. I cannot see that. Partial differential equations have propagation properties as rigorous as those of ordinary differential equations and causality finds its place within the lightcone of relativistic physics. Further, I did not understand his attitude to mathematics. He does not like to accord it true intellectual independence (that would be dangerously Platonic and Plato's ideas are possible rivals to God in his eyes) so he says it has a "natural bond with nature". Again, I do not see that.

The book is written in a style which might be described as "Scottish professorial", a sort of intellectual cousin to the elaborate castellation of Scottish baronial. Certainly, it does not make for easy reading or rapid assimilation.

John Polkinghorne, formerly Professor of Mathematical Physics at Cambridge, is a Fellow of Trinity College and an Anglican clergyman.

\section{How not to make a splash in science}

\section{Robert Ubell}

Polywater. By Felix Franks. Pp.208. ISBN 0-262-06073-6. (MIT Press: 1981.) \$15, $£ 9.30$.

In the early 1960 s in an obscure laboratory in Kostroma, 190 miles from Moscow on the upper Volga, an equally obscure research scientist, Nikolai Fedyakin, stumbled on a surprising phenomenon. Looking at how liquids behave in very narrow capillaries, he watched as a dense new liquid formed in neighbouring empty tubes.

In Moscow, the renowned physical chemist B.V. Deryagin quickly recognized the possible implications of Fedyakin's "discovery" and took it for his own. He set an entire laboratory to work on it, published results widely and campaigned for the recognition of anomalous water at Faraday Society and Gordon Research conferences. The new liquid was 15 times denser than normal water, boiled at temperatures much higher than $100^{\circ} \mathrm{C}$ and froze, without forming ordinary ice, at under $-30^{\circ} \mathrm{C}$. For a time, Western scientists either yawned or sneered. Some guessed it wasn't water at all, but the result of contamination. Yet excitement grew, and in England attempts were made to replicate the Russian work. J.D. Bernal, in private, called Deryagin's achievement "the most important physical-chemical discovery of this century".

The US Office of Naval Research jumped in next, sensing that the mysterious new form of water might have military uses. Ripples of interest swelled to waves: the liquid was given a name - polywater and busy scientists suddenly found the time and money to work on what they had seen as a mere curiosity the previous week. Respected researchers and the overzealous alike scrambled to make their mark, even though, at most, only a few drops of polywater had ever been collected.

In 1973 the bubble burst. In a brief, dignified note in Nature, Deryagin reported that he and his colleagues had finally found it impossible to grow polywater from ordinary water. The unique qualities claimed earlier "should be attributed to impurities rather than to the existence of polymeric water molecules". The emperor was not well dressed.

Felix Franks escaped the perils of the polywater controversy, but as a distinguished surface chemist and an authority on water he was close enough to record it all. The result is this book. To his great credit, Franks treats those who believed and those who didn't with an even hand, praising little, blaming less. This is a skilfully made book, wise, urbane,

\section{Nature of "Anomalous Water"}

MANY experiments have corroborated the phenomenon involving the formation of condensates with anomalous properties from the vapours of water and other liquids on silicate surfaces. But the nature of this phenomenon remained obscure for a long time and widely differing hypotheses were put forward to clarify it, one of them involving the formation of stable associates of water molecules $\left(\mathrm{H}_{2} \mathrm{O}\right)_{\mathrm{n}}$. This hypothesis was first formulated by $\mathrm{us}^{1-4}$ and was developed further by Lippincott et al. ${ }^{5,0}$.

We have established that there are no condensates both free of impurity atoms and simultaneously exhibiting anomalous properties. Consequently, these properties should be attributed to impurities rather than to the existence of polymeric water molecules.

Consequently, the anomalous properties of condensates may be explained, not by the formation of a new modification o water, as was previously supposed, but by the peculiar features of a reaction taking place between the vapour and solid surfaces in the process of condensation. Many aspects of the mechanism of formation of anomalous condensates have not yet been fully clarified. This especially applies to the formation of anomalous condensate on $\mathrm{MgO}$ surfaces ${ }^{19,20}$. Only the general features of the phenomenon are clear as yet; thorough investigation by those studying processes involving the interaction of vapours and solid surfaces is clearly required.

$\begin{array}{ll}\text { The Institute of Physical Chemistry, } & \text { B. V. DERJAGUIN } \\ \text { USSR Academy of Sciences } & \text { N. V. CHURAEV }\end{array}$

The end of polywater. Extracts from the paper by Deryagin (Derjaguin) and Churaev, published in Nature on August 17, 1973. 